\title{
Murine basal cell carcinoma leads to tumor-mediated alterations in endocrine Igf1 signaling
}

\author{
Rehan M Villani ${ }^{1}{ }^{1}$, Michael J Waters ${ }^{1}$ and Brandon J Wainwright ${ }^{1}$ \\ ${ }^{1}$ Institute for Molecular Bioscience, University of Queensland, 360 Carmody Road, St Lucia, Brisbane, Queensland \\ 4072, Australia \\ 2Department of Dermatology, CMMC, University of Cologne, Robert Koch Street 21, 50931 Cologne, Germany
}

\begin{abstract}
The intrinsic properties underlying cancer development are extensively studied while the effect of a cancer on the host is often overlooked. Activation of the Hedgehog $(\mathrm{Hh})$ signaling pathway underlies a number of types of common human cancers, yet little is known concerning endocrine signaling in such tumors. Here, we investigated endocrine signaling in a murine model of basal cell carcinoma (BCC) of the skin, the most common cancer. BCCs were generated by the activation of Hh signaling resulting from the specific deletion of the Ptch1 gene in the developing epidermis. Subsequently, a severe growth deficiency was observed in the murine BCC model, and we identified a deficiency of circulating IGF1 (Igf1). We demonstrate that Hh pathway activation in murine BCC induces IGF binding proteins, thereby regulating Igf1 sequestration into the skin and skewing Igf endocrine signaling. Significantly, these results show that Hh-induced tumors can have endocrine effects on normal tissues that in turn can greatly impact the host. This study not only identifies that lgf is important in Hh-associated skin tumors but also exemplifies the need to consider endocrine signaling when interpreting complex in vivo tumor models.
\end{abstract}

Correspondence should be addressed to B J Wainwright Email b.wainwright@ imb.uq.edu.au

\section{Introduction}

It is becoming increasingly recognized that the interaction between solid tumors and their supporting stroma is a key determinant of tumor initiation and growth. While the molecular basis of tumor initiation and growth within the tumor itself is studied comprehensively in a number of systems, much less is known of the manner or mechanism in which a tumor influences its immediate environment, and the host as a whole. Hedgehog (Hh) signaling is central to the development of many tumor types, including basal cell carcinoma of the skin (BCC; Hahn et al. 1996, Diepgen \& Mahler 2002, Adolphe et al. 2006), the most common cancer in humans. In a number

$\begin{aligned} & \text { Key Words } \\ & \text { - Patched } 1 \\ & \text { - skin } \\ & \text { - IGF } \\ & \text { - } \text { BCC }\end{aligned}$


The majority of BCC arise from mutation of Patched1 (Ptch1; Gailani et al. 1996, Wicking \& Bale 1997). Ptch 1 is a transmembrane receptor that maintains the Hh signal in an inactive state (Chen \& Struhl 1998) but direct binding of Hh ligands to Ptch1 causes the Hh pathway to become active through disrupting the interaction between Ptch1 and another member of the signaling complex, Smoothened. Thus, the Hh pathway can be activated in a paracrine fashion by $\mathrm{Hh}$ ligands, or cell autonomously activated by loss of Ptch1 function. The net result of Hh pathway stimulation is an increase in activated Gli transcription factors, which promote target gene expression. In BCC, mutation of Ptch1 results in inappropriately activated Hh signaling, increased Gli transcription factors, and expression of cell cycle genes cyclin D1 and Myc (Adolphe et al. 2006, Nieuwenhuis et al. 2007). Aberrant cell cycle regulation causes uncontrolled proliferation within the epidermal basal cell compartment, ultimately resulting in BCC.

In some contexts, the $\mathrm{Hh}$ pathway can regulate growth factors known for both endocrine and paracrine signaling and often associated with cancer, including IGF (Igf; Hahn et al. 2000, Bigelow et al. 2005, de Bont et al. 2008). Igf signaling is of particular importance as it coordinates growth and proliferation throughout the body. Igf1 is the primary mediator of GH-induced growth and coordinates postnatal growth of nearly every tissue (Baker et al. 1993). Igf signaling has also been implicated in Hh-induced medulloblastoma and rhabdomyosarcoma as it appears that Igf2 synergizes with $\mathrm{Hh}$ signaling to promote tumorigenesis (Hahn et al. 2000). We have also previously demonstrated Hh signal regulation of Igf signal components including Igf2 in mesenchymal cells in vitro and Igfbp2 in Hh-induced BCC (Ingram et al. 2002, Villani et al. 2010). However, despite multiple reports of $\mathrm{Hh}$ regulation of Igf, much remains to be investigated regarding the $\mathrm{Hh}$ and Igf interaction in the initiation, development, and metastasis of cancer.

Here, we investigated endocrine signaling in a Hh-activated tumor model in order to better understand secondary growth phenotypes commonly associated with the development of cancer. We show that mice with the $\mathrm{Hh}$ pathway activated in Keratin 14 expressing cells develop BCC and also manifest a significant postnatal growth defect associated with low circulating Igf1 levels. The Hh-activated epidermis has dysregulated local production of Igfbps and sequester-free Igf1. The sequestration of Igf1 in Hh-activated skin provides a link between low serum Igf1 levels evident in the growth-retarded, BCC-prone mice. These data not only indicate a pathological link between
Hh and Igf1 signaling but also illustrate a novel mechanism whereby even a highly localized tumor can have profound systemic endocrine effects.

\section{Materials and methods}

\section{Mice}

Mice were bred via crossing Ptch 1 conditional mice with a K14-Cre recombinase line, genotyped via PCR as previously published (Jonkers et al. 2001, Ellis et al. 2003). Cre recombinase function was tested via crossing K14-Cre mice to a Z/AP indicator line (K14-Cre:Z/AP) (Lobe et al. 1999). Mice were housed in light-controlled facility and work performed according to institutional ethics requirements. Mice were weighed daily and at collection to determine growth curve. Blood was collected via cardiac puncture after IP of xylazine hydrochloride, $13 \mathrm{mg} / \mathrm{kg}$ (Ilium Xylazil-20), and tiletaminezolazepam, $33 \mathrm{mg} / \mathrm{kg}$ (Zoletil-50), diluted to $5 \%(\mathrm{v} / \mathrm{v})$ solution in saline. Samples were centrifuged at $6153 \boldsymbol{g}$ for $15 \mathrm{~min}$ at $4{ }^{\circ} \mathrm{C}$, serum decanted, and then at $15350 \boldsymbol{g}$ for $10 \mathrm{~min}$ at $4^{\circ} \mathrm{C}$. Pathology was recorded upon dissection and all organs were inspected. Organs were weighed and percentages from whole body weight were calculated.

\section{Histology}

Hematoxylin and eosin staining was performed as previously published (Villani et al. 2010). K14-Cre:Z/AP tissues were embedded in OCT compound (Tissue-Tek 4583 ) for sectioning or fixed in $0.2 \%$ glutaraldehyde for whole mount, all other histology was performed on paraffin-embedded tissue. Alkaline phosphatase (AP) staining performed post-PBS wash with AP fix $(0.2 \%$ glutaraldehyde, $50 \mathrm{mM}$ EGTA, $100 \mathrm{mM} \mathrm{MgCl}_{2}, 0.02 \%$ NP-40, $0.01 \%$ Na-deoxycholate, and $2 \mathrm{mM} \mathrm{MgCl}_{2}$, in PBS), incubation at $70{ }^{\circ} \mathrm{C}$ for $30 \mathrm{~min}$ in PBS, and $2 \times \mathrm{PBS}$ washes. Slides were then washed $10 \mathrm{~min}$ in AP buffer (100 mM Tris- $\mathrm{HCl}, \mathrm{pH} 9.5,100 \mathrm{mM} \mathrm{NaCl}$, and $10 \mathrm{mM}$ $\mathrm{MgCl}_{2}$ in $\mathrm{H}_{2} \mathrm{O}$ ) followed by color incubation with $\mathrm{BM}$ purple AP substrate (Roche 11442074001 ) at $4{ }^{\circ} \mathrm{C}$ for 0.5-36 h. Slides were then washed with $0.1 \%$ Tween 20 , $2 \mathrm{mM} \mathrm{MgCl}_{2}$ in PBS, dehydrated, and mounted with Entellan. Whole mount AP staining was performed similarly but samples were stored at $4{ }^{\circ} \mathrm{C}$ in AP buffer.

\section{Hormone and nutrient analysis}

Nutrient values were determined using whole blood. GH levels were assayed using Linco rat GH RIA kit,

Published by Bioscientifica Ltd 
RGH-45HK, as per manufacturer's instructions. GH receptor (GHR) activation was assayed after administering $4 \mu \mathrm{g} / \mathrm{g}$ GH IP to p19 K14-Cre:Ptch1 $1^{\text {lox/lox }}$ mice and control littermates followed by liver collection $15 \mathrm{~min}$ post-injection. JAK2 and STAT5 were assayed via immunoprecipitation (IP) from whole liver protein and the tyrosine-phosphorylated fraction determined. IP was performed on whole fresh frozen protein extract in IP lysis buffer (50 mM Tris, pH 8.0, $150 \mathrm{mM} \mathrm{NaCl}, 1 \mathrm{mM} \mathrm{Na}$ vanadate, $10 \mathrm{mM} \mathrm{NaF}$, and $0.6 \%$ Triton-X-100). Protein A (40 $\mu$ l) (Sigma P3391) or protein G (Sigma P3296) fast flow sepharose was blocked in 1\% BSA in TBS for 2-4 h. Beads washed twice with lysis buffer were then incubated with $2 \mu \mathrm{g}$ of antibody Jak2 (Santa Cruz sc-278) or Stat5 (Santa Cruz sc-835) in lysis buffer at $4{ }^{\circ} \mathrm{C}$ rotating overnight. Protein $\left(40 \mathrm{mg}\right.$ ) was then incubated rotating $2 \mathrm{~h}$ at $4{ }^{\circ} \mathrm{C}$. Samples were centrifuged, washed twice with PBS, heated for $5 \mathrm{~min}$ at $100^{\circ} \mathrm{C}$, and were then extracted in Laemelli sample buffer. Samples were separated via polyacrylamide electrophoresis and probed for phosphorylated and total JAK2 and STAT5.

\section{Igf and Igfbp analysis}

Skin segments were homogenized in RIPA buffer $(50 \mathrm{mM}$ Tris- $\mathrm{HCl}, 150 \mathrm{mM} \mathrm{NaCl}, 0.5 \%$ Na-deoxycholate, $1 \%$ NP-40, and $0.1 \%$ SDS) containing protease inhibitor (Roche 1697 489) and PhosphoSTOP phosphatase inhibitor (Roche 04906837001). Samples were sonicated $2 \times 30 \mathrm{~s}$ and centrifuged at $13000 \mathrm{~g}$ for $30 \mathrm{~min}$ at $4{ }^{\circ} \mathrm{C}$. Igf binding proteins (Igfbps) were removed using Bioclone in assay acid-ethanol extraction before determination of Igf levels via RIA (Bioclone cat number IGF50) or ELISA (R\&D duoset DY791) as per manufacturer's instructions. Igf ligand blot analysis was performed on equal volumes of protein separated via polyacrylamide electrophoresis probed with $0.2 \mu \mathrm{g} / \mathrm{ml}(1 \mu \mathrm{g} / \mathrm{blot})$ biotinylated Igf1 (Gropep AQU050) detected with streptavidin-HRP and chemiluminescence (Amersham, RPN2106). Binding proteins were identified by size compared to protein ladder (Fermentas SM0671).

\section{RNA analysis}

RNA was prepared from whole skin using QIAgen RNAeasy fibrotic kit (QIAgen 74704). cDNA was prepared from 500 ng RNA and RT was performed using M-MLV reverse transcriptase (Invitrogen 28025-013). Taqman inventoried assays were purchased from Applied Biosystems (Mm00833447, Mm00492632m1, Mm00515156m1,
Mm00494922m1, Mm00516037, and Mm00599696m1) and real-time PCRs were performed on 7000 and 7500 RealTime and analysis was performed using ABI prism 7000 SDS software.

\section{Explant culture}

Explant culture was performed on p19 skin as previously published (Villani et al. 2010) with biotinylated Igf1 (Gropep, Adelaide, SA, Australia; AQU050) added to explants at isolation. Biotin was then detected on sections after 30-min ABC treatment (Vector Labs, Burlingame, CA, US; PK-6101) with DAB peroxidase substrate (Vector Labs KK-4100).

\section{Statistical analysis}

Statistical analyses were performed using Word Excel and ABI prism statistical software and analyses performed are indicated in figure text.

\section{Results}

K14-Cre recombinase-induced deletion of Ptch1 results in severe growth deficiency

Epidermal deletion of a Ptch1 conditional allele via K14-Cre recombinase (K14-Cre:Ptch1 ${ }^{\text {lox/lox }}$ mice) results in the development of BCC lesions before 4 weeks of age (Villani et al. 2010). Concomitant with BCC development, K14-Cre:Ptch1 $1^{\text {lox/lox }}$ mice present with a severe growth deficiency and K14-Cre:Ptch $1^{\text {lox/lox }}$ mice $(13.0 \mathrm{~g} \pm 0.54$, $n=34)$ do not progress beyond $49 \%$ of control littermate weight (26.6 $\mathrm{g} \pm 0.60, n=67)$ (Fig. 1A). Weight differences are equivalent between sexes (Fig. 1B) and significant differences are first observed around postnatal day 19 (Fig. 1C), the same age as hyperproliferative lesions were observed to first develop in the skin (Supplementary Figure 1, see section on supplementary data given at the end of this article). Organ weight percentages of total body weight show that K14-Cre:Ptch $1^{\text {lox/lox }}$ mice are proportionally smaller than control littermates and do not identify a candidate tissue mediating a growth defect in K14-Cre:Ptch1 ${ }^{\text {lox/lox }}$ mice (Fig. 1D).

\section{K14-Cre:Ptch $1^{\text {1ox/lox }}$ mice have abnormalities of the skin and thymus}

Whole body growth can be influenced by many factors from a number of different tissues. K14-Cre-mediated Ptch1 mutation may also occur in stratified epithelia

Published by Bioscientifica Ltd 

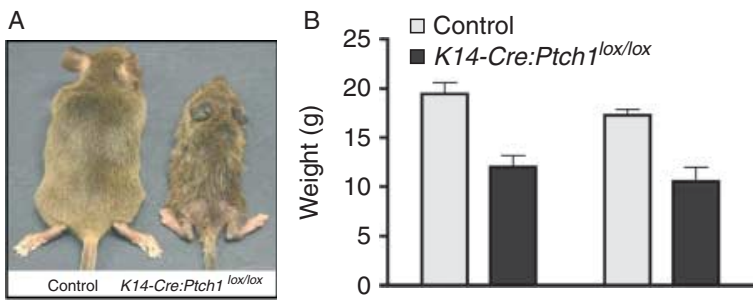

C $40 \ldots$ A Control $\square$ K14-Cre:Ptch1 $10 x / 10 x$


Figure 1

K14-Cre:Ptch $1^{\text {lox/lox }}$ mice have growth defects. Size differences between K14-Cre:Ptch $1^{\text {lox/lox }}$ mice $(13.0 \mathrm{~g} \pm 0.54, n=34)$ and littermates (26.6 $\mathrm{g} \pm 0.60, n=67)$ are obvious at p32 (A). At 24 days old, both male and female $K 14$-Cre:Ptch $1^{\text {lox/lox }}$ mice are around $50 \%$ of control littermate weight (B). Growth retardation in $K 14-C r e: P t c h 1^{\text {lox/lox }}$ mice begins postnatally, around 19 days old $(C), P$ value $=0.002$ calculated using one-way ANOVA. K14-Cre:Ptch $1^{\text {lox/lox }}$ mice are proportionally smaller than littermates, a number of organs show a comparable ratio of organ to total body weight in $\mathrm{K} 14-\mathrm{Cre}:$ Ptch $1^{\text {lox/lox }}$ mice compared to littermate controls (D).

beyond the epidermis (Jonkers et al. 2001). To further characterize K14-Cre function, K14-Cre mice were bred with a Z/AP allele (Lobe et al. 1999), such that alkaline phosphatase (Alk. Phos.) staining of K14-Cre:Z/AP tissue indicates Cre recombinase function. Alk. Phos. staining identified K14-Cre-induced recombination in the skin (Fig. 2B), thymus (Fig. 2A and E), testes (Fig. 2F), and bladder lining (Fig. 2D) but not in many endogenous K14 expressing tissues including the pituitary, lung (Fig. 2C), nasal septum, and esophagus (Fig. 2H). No phenotypic differences between K14-Cre:Ptch1 ${ }^{\text {lox/lox }}$ mice and littermates were identified in the esophagus (Fig. 3A and B), stomach (Fig. 3C and D), colon (Fig. 3E and F), kidney, and liver (data not shown). In addition to the skin,
K14-Cre:Ptch $1^{l o x / l o x}$ mice were found to have a hypoplastic thymus (Fig. 3G), which we have previously characterized as an alteration in T-cell maturation (Siggins et al. 2009). K14-Cre:Ptch $1^{\text {lox } / l o x}$ mice do not breed successfully, indicating that K14-Cre:Ptch ${ }^{\text {lox/lox }}$ mice may also have a gonadal phenotype. Finally, analyses of serum nutrients (Fig. 2F) revealed no significant differences between K14-Cre:Ptch1 $1^{\text {lox/lox }}$ and littermate controls.

\section{Growth deficit is associated with decreased circulating lgf1}

The proportional growth deficit observed in K14-Cre: $P t c h 1^{l o x / l o x}$ mice, in the absence of any clear organ defect, is suggestive of a hormonal alteration. First, we examined $\mathrm{GH}$ as a possible cause of the observed growth deficiency,
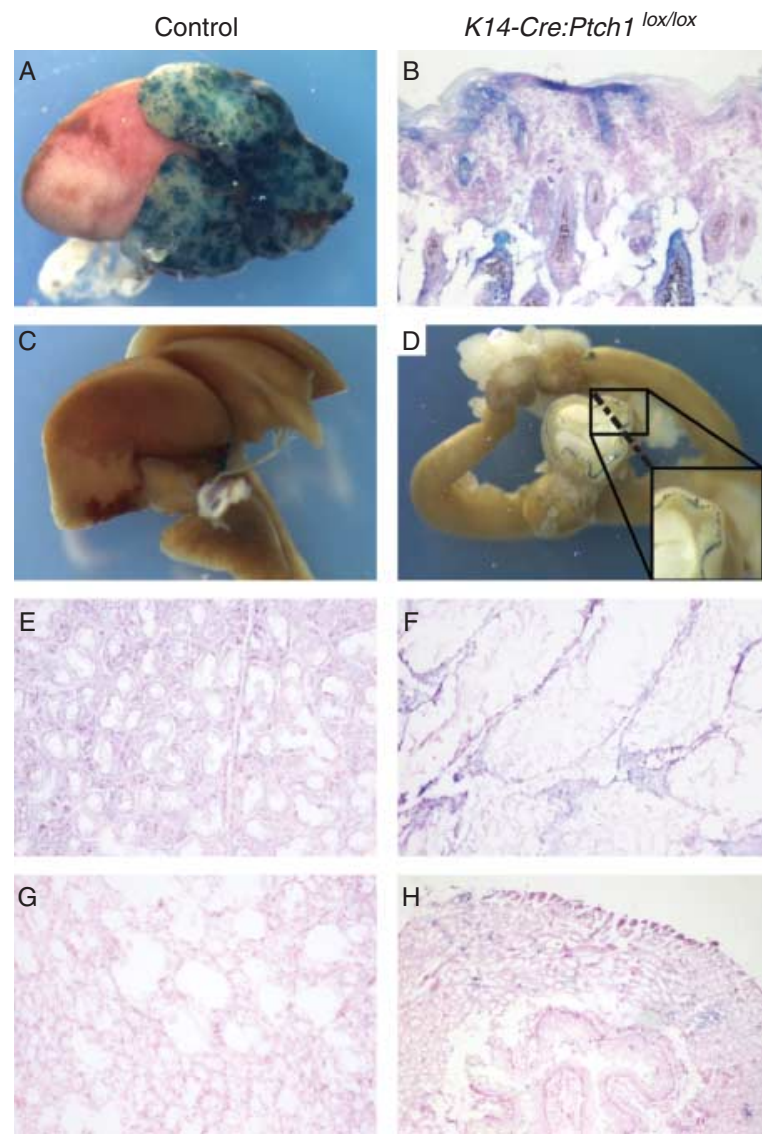

\section{Figure 2}

K14-Cre function is observed in a number of epithelia. Alkaline phosphatase (Alk. Phos.) staining of K14-Cre:ZIAP mice showed Cre recombinase activity in the thymus but not the heart (A) and the skin (B). The lung (C) and the majority of the urogenital tract (D) do not stain positively for Alk. Phos. though staining can be seen in the bladder lining (inset) indicating Cre recombinase function. Staining of sections shows Alk. Phos. expression in thymic epithelium (E) and testes (F) but not the lung (G) or esophagus $(\mathrm{H})$. 


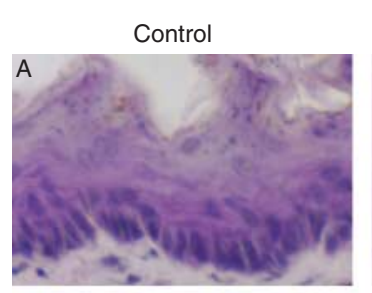

K14-Cre:Ptch $1^{\text {lox/lox }}$
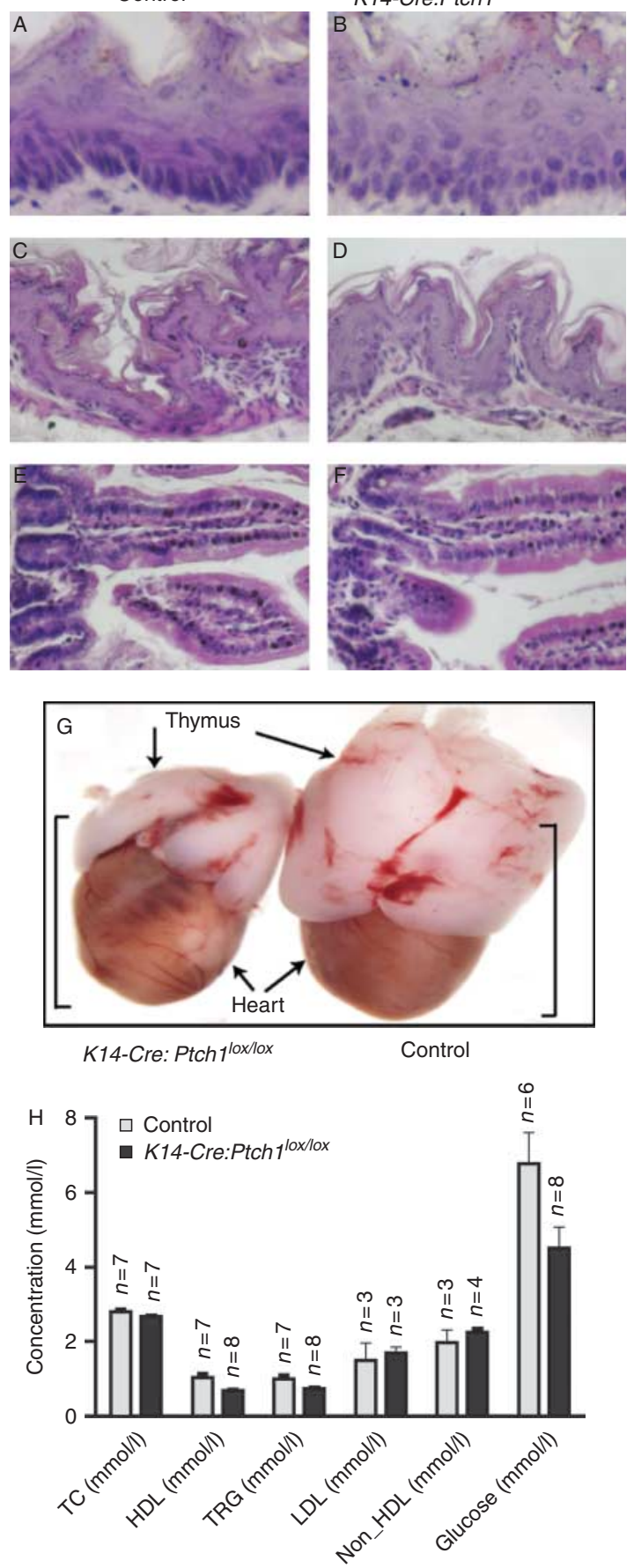

Figure 3

K14-Cre:Ptch $1^{\text {lox/lox }}$ mice have minimal defects beyond the skin. Histological staining showed no discernable differences between control and K14-Cre:Ptch $1^{\text {lox/lox }}$ mice in the esophagus (A and B), stomach (C and D), or small intestine ( $E$ and $F$ ). The only observable defect by gross investigation in $\mathrm{K} 14-\mathrm{Cre}: \mathrm{Ptch} 1^{\text {lox/lox }}$ mice is a decreased thymus size (G). It is also notable that no significant differences were observed in major serum macronutrients, $n$ value indicated in graph $(\mathrm{H})$. but this appears unlikely as plasma GH levels (Fig. 4A) and STAT5/JAK2 (Fig. 4B and C) signal activation are normal in K14-Cre:Ptch1 ${ }^{\text {lox/lox }}$ mice. Due to similarity between growth curves in K14-Cre:Ptch1 $1^{\text {lox/lox }}$ and that observed for Igf1 null mice (Baker et al. 1993), we then examined Igf1 serum levels. Serum Igf1 levels are markedly reduced in K14-Cre:Ptch1 $1^{\text {lox/lox }}$ mice (Fig. 4D) and consequently may be involved in the observed growth alteration. While a decrease in $I g f 1$ transcript levels in the liver was observed (Fig. 4E), no gross morphological abnormalities nor evidence of $\mathrm{Hh}$ signal alteration in the liver of K14-Cre:Ptch1 $1^{\text {lox/lox }}$ mice were observed. Furthermore, Igf level alterations do not correlate with altered serum Igfbp levels, as Igfbp1,Igfbp2, and Igfbp5 do not change in K14-Cre:Ptch1 ${ }^{\text {lox/lox }}$ serum (Fig. 4F). Accordingly, we examined the possibility that the observed levels of circulating Igf1 are not due to phenotypic alterations in K14-Cre:Ptch $1^{\text {lox/lox }}$ liver but are controlled from another tissue. Due to the severity of the growth phenotype and correlated development of BCC and growth defects in K14-Cre:Ptch1 $1^{\text {lox/lox }}$ mice, the skin was investigated for a possible role in the regulation of Igf1 levels.

\section{Hh signaling activation in the skin alters Igfbp expression and results in Igf1 sequestration}

Igfbps are modulators of Igf signaling and we have previously defined members as Hh signaling targets (Ingram et al. 2002). Accordingly, we next investigated the hypothesis that aberrant regulation of Igfbps in the skin of K14-Cre:Ptch1 $1^{l o x / l o x}$ mice could contribute to the low serum Igf1 levels in these mice. Analysis of skin Igfbp transcript levels revealed alterations in $I g f b p 2$, Igfbp4, and Igfbp5 after epidermal Ptch1 deletion (Fig. 5). Igfbp1 and $I g f b p 6$ were not detectable in skin and $I g f b p 3$ showed no alterations after Ptch1 deletion (Fig. 5). As previously published, $I g f b p 2$ appeared positively associated with BCC development (Fig. 5B) and was significantly increased in adult Ptch1-deleted skin (Villani et al. 2010) while Igfbp4 was decreased in adult Ptch1-deleted skin (Fig. 5F). Igfbp5 was decreased significantly in 10-day-old K14-Cre:Ptch1 ${ }^{\text {lox/lox }}$ skin compared with controls (Fig. 5G); however, this was no longer statistically significant at 6 weeks of age. These results support the possibility that Igfbp alteration in K14-Cre:Ptch1 $1^{\text {lox/lox }}$ skin may affect circulating Igf1 levels, thereby contributing to the observed reduced serum Igf1 levels. In order to test this hypothesis, we analyzed the ability of K14-Cre:Ptch1 $1^{\text {lox/lox }}$ skin to recruit biotinylated Igf1 (B-Igf1) ligand in explant culture. B-Igf1 could not be detected in control skin

Published by Bioscientifica Ltd 
A

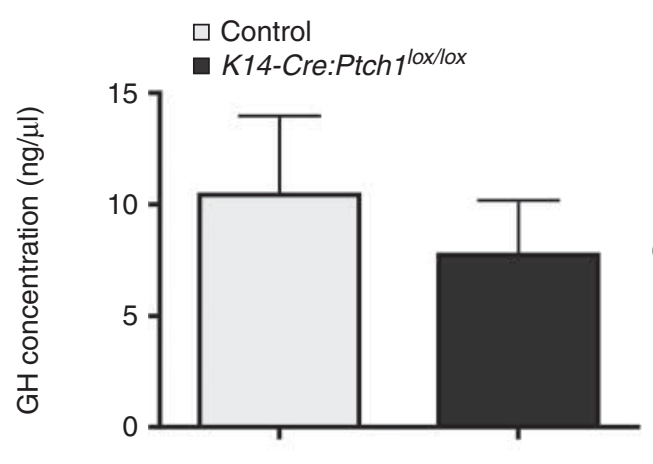

D

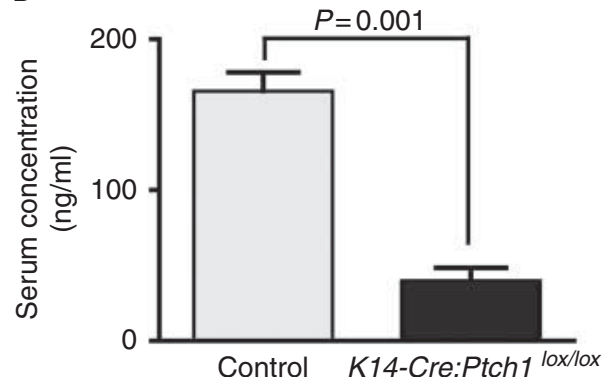

$\mathrm{E}$



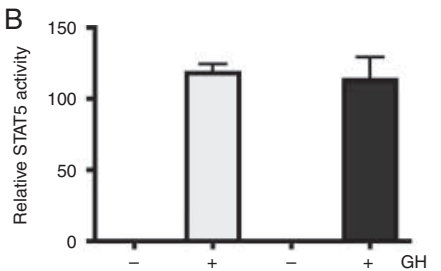

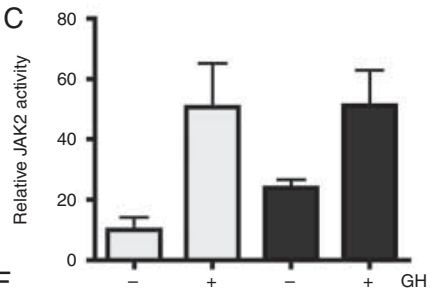

$\mathrm{F}$
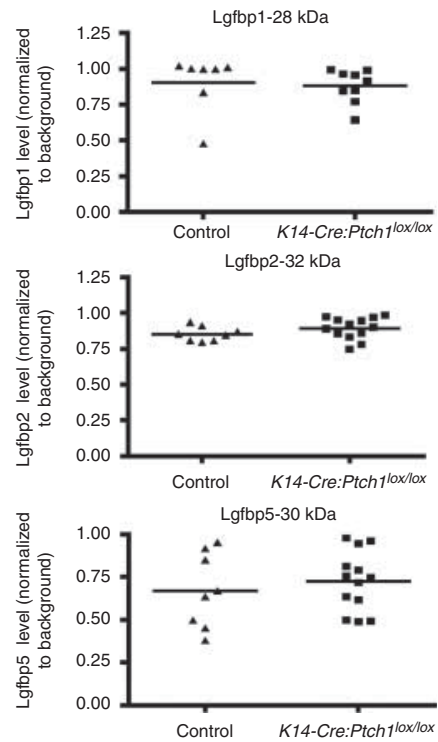

Figure 4

Growth defects in K14-Cre:Ptch $1^{\text {lox Ilox }}$ mice are associated with systemic Igf1 deficiency. GH levels (A) do not differ between controls and K14-Cre:Ptch $1^{\text {lox/lox }}$ mice and GH induces JAK2 (B) and STAT5 (C) in K14-Cre:Ptch $1^{\text {lox/lox }}$ mice similar to controls. Igf hormone levels are greatly decreased in $\mathrm{K} 14$-Cre:Ptch $1^{\text {loxllox }}$ plasma compared with controls (D) and Igf

explants or non-B-Igf-treated cultures, despite a healthy proliferating appearance (Fig. 6). By contrast, B-Igf could be detected histochemically in epidermal cells of K14-Cre: Ptch $1^{\text {lox/lox }}$ skin explants (Fig. 6). These data suggest that K14-Cre:Ptch1 $1^{\text {lox/lox }}$ skin can recruit Igf1 into the skin, indicating that these mice are likely growth deficient due to sequestration of Igf1 hormone into the skin and away from the majority of other growing systems.

\section{Discussion}

This study has identified a link between Igf signaling and Hh signaling in skin cancer due to a severe growth transcript levels are also decreased in the liver (E). Densitometry of Igf ligand blots shows that circulating Igf binding protein levels are similar between controls and $K 14-C r e: P t c h 1^{\text {lox/lox }}$ mice (F). $P$ values were calculated by two-tailed Student's $t$-test.

deficiency identified during investigations into BCC development in K14-Cre:Ptch1 $1^{\text {lox/lox }}$ mice. Endocrine regulation appears to be far more important in this system than one would expect, and this study clearly shows how important it is to consider not just local but also systemic effects in complex murine models of cancer.

Here, we observed that epidermal loss of Ptch1 in K14-Cre:Ptch1lox/lox mice leads rapidly to both BCC development and growth retardation (3-4 weeks postdeletion). Coincident with these phenotypes, circulating Igf1 levels drop and its absence during the postnatal growth spurt (around 20 days old in mice) is a likely cause of the growth deficiency. We propose that BCC 

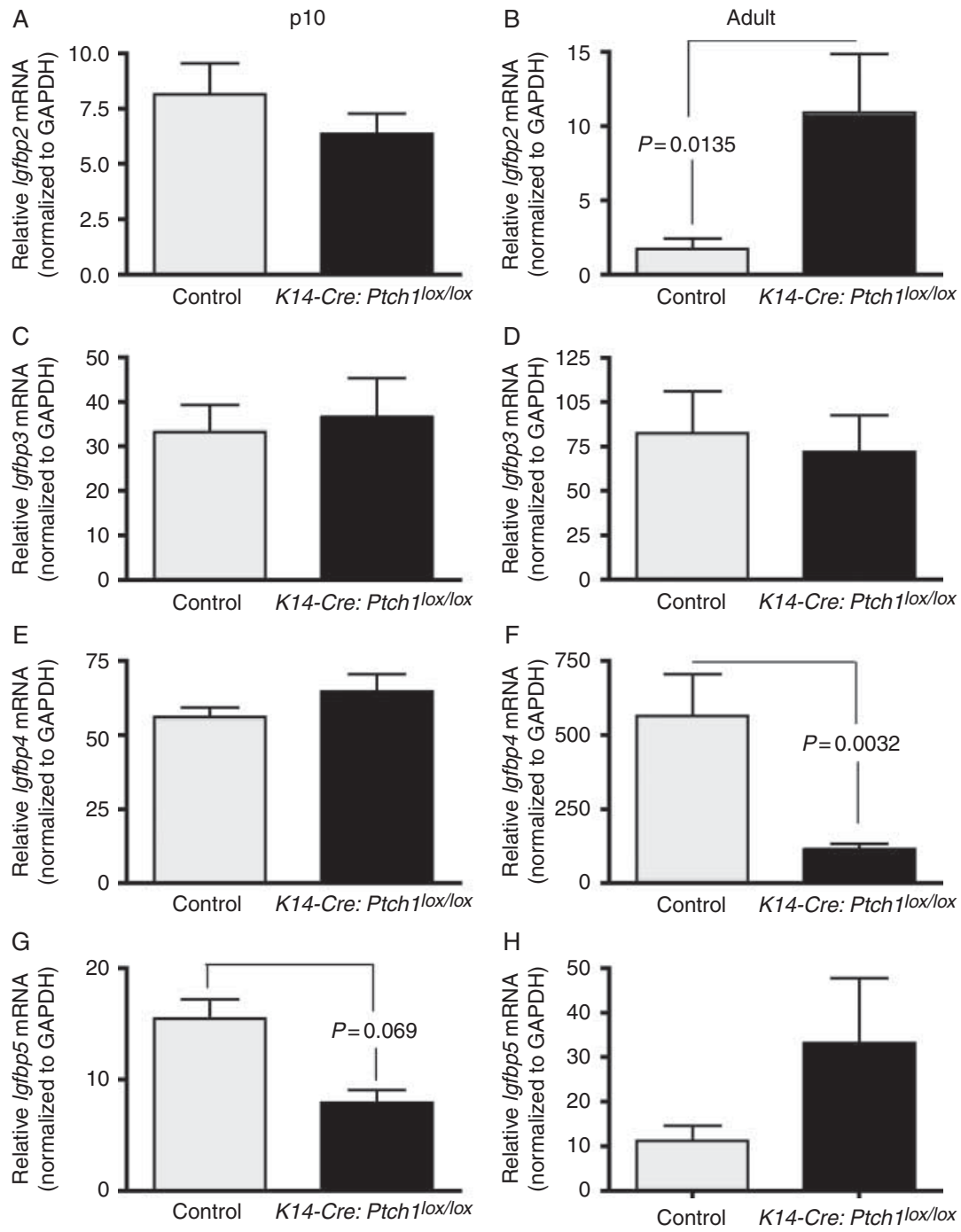

Figure 5

K14-Cre:Ptch1 10xllox skin has alterations in lgfbp levels. Igfbp2 (A and B), lgfbp3 (C and D), Igfbp4 (E and F), and Igfbp5 ( $\mathrm{G}$ and H) mRNA levels in whole skin were determined by real-time RT-PCR. Significant increases were seen in the levels of $/ g f b p 2$ in adult $K 14-C r e: P t c h 1^{\text {lox/lox }}$ skin compared

with littermate controls (B) while decreases were seen in Igfbp4 (F) in adult K14-Cre:Ptch $1^{\text {lox/lox }}$ skin and lgfbp5 in p10 (G) skin compared with control littermates.

development is causal in reducing circulating Igf1 levels, which results in the observed growth deficiency. In addition to an epidermal-based model, many alternative causes for growth retardation in K14-Cre:Ptch $1^{\text {lox/lox }}$ mice were investigated here. However, no clear extra-epidermal mechanism for the growth defect could be found. For example, we found no evidence for impaired food absorption, as serum nutrients and gut morphology were not altered (Fig. 3F), or altered liver phenotype (data not shown). While a decrease in the transcript level of $I g f 1$ was observed in the liver, we propose that this is not causal for the growth deficiency as liver-specific Igf1 deletion

resulting in complete ablation of liver Igf1 production does not result in growth deficiency; therefore, it is unlikely that the small changes in transcript level in K14-Cre:Ptch $1^{\text {lox } / \text { lox }}$ mice cause the observed growth defect (Yakar et al. 1999).

The epithelial specific nature of Ptch1 deletion in this model indicates that an epithelial source of growth retardation is most likely. Hh signaling has been shown to interact with Igf signaling in other models. For example, in the cerebellar tumor medulloblastoma, $\mathrm{Hh}$ signaling promotes Igf 2 signaling and thereby recruits Igf 2 into the tumor from circulation (Rao et al. 2004). In a

Published by Bioscientifica Ltd. 


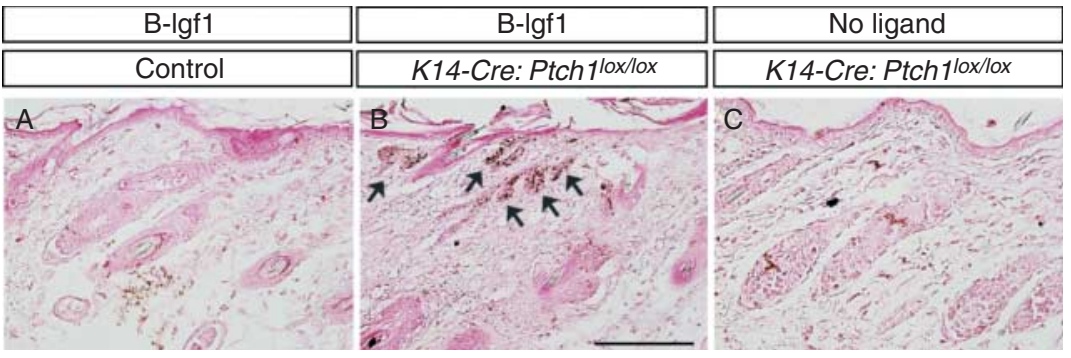

\section{Figure 6}

K14-Cre:Ptch $1^{\text {lox/lox }}$ skin explants recruit biotinylated Igf1 ligand. Control explant cultures treated with biotinylated Igf1 (B-Igf) (A) show no detectable biotin levels while in $\mathrm{K} 14-\mathrm{Cre}:$ Ptch $1^{\text {lox/lox }}$ explant cultures B-Igf1

tissue as large as the skin, and considering the amplification in cell number that occurs as a result of BCC in K14-Cre:Ptch1 $1^{l o x / l o x}$ mice, it is likely that a similar Igf recruitment processes would mediate large overall changes in hormone levels. As Igfbps are known to regulate serum levels of Igf1, we hypothesized that Igfbp production in Ptch1-deleted epidermis modulates circulating Igf levels. This contention was supported by the upregulation of Igfbps with a high Hh signal and the demonstration of the ability of K14-Cre:Ptch $1^{\text {lox/lox }}$ skin to recruit Igf1 ligand. The data do not support the possibility that the observed low levels of serum Igf1l is due to Igfbp release into the circulation as circulating Igfbp levels do not appear to be altered (Fig. 3). On the basis of these data, we propose that Igf1 is being recruited into the skin where it may facilitate BCC proliferation and consequently lead to decreased circulating Igf1, which manifests as a secondary growth defect.

The data presented here indicate that Ptch1 mutation is modulating the Igf axis in the skin. Igfbp alteration may reflect an altered cell-type composition in the skin and suggest that Igfbps mediate Hh regulation of skin homeostasis. Igfbp5 regulates hair follicle growth (Schlake 2005), and therefore, Igfbp5 downregulation in K14-Cre:Ptch1 $1^{\text {lox/lox }}$ skin most likely reflects the hair loss that occurs concomitant with BCC development in K14-Cre:Ptch1 ${ }^{\text {lox/lox }}$ skin. We have previously demonstrated that Igfbp2 is a key regulator of progenitor cell regulation and BCC development in K14-Cre:Ptch ${ }^{\text {lox/lox }}$ skin (Villani et al. 2010). The data presented in this study indicate that Igfbp4 is negatively associated with BCC and this observation remains to be further investigated. Igfbps are known to be targets of $\mathrm{Hh}$ signaling in tissues other than skin (Ingram et al. 2002, Allan et al. 2003, Lipinski et al. 2005, Villani et al. 2010), which in combination with these results suggest that (brown color indicated by arrows) is observed in the basal epidermis (B). No biotin staining is seen in explant cultures without B-lgf1 treatment (C).

Igfbps in general may represent important tissue-specific mediators of Hh signaling.

Interestingly, Hh signal alterations are associated with as yet unexplained body size phenotypes. Murine models of Hh signal alteration have been described as having a growth alteration (Milenkovic et al. 1999) and increased body size is seen in the human syndrome nevoid BCC syndrome in which patients carry a heterozygote Ptch1 mutation (Gorlin 2004). Gorlin syndrome patients' carry whole body heterozygote Ptch1 mutation, quite different from the BCC model discussed within this work, which has epithelial specific homozygous Ptch1 mutation. In combination with other published data showing Igfbps are common, tissue specific Ptch1 targets this indicates that Igf signaling should be considered as a likely contributor to Gorlin syndrome and other Hh related growth phenotypes and therefore Igf action may be of broader relevance to the many human disease conditions caused by Hh signal modulation.

\section{Supplementary data}

This is linked to the online version of the paper at http://dx.doi.org/10.1530/ ERC-12-0307.

\section{Declaration of interest}

The authors declare no conflict of interest that could be perceived as prejudicing the impartiality of the research reported.

\section{Funding}

This work was financially supported by the National Health and Medical Research Council of Australia.

\section{Acknowledgements}

The authors would like to thank David Curtis, Sarah Siggins, Dagmar Wilhelm, Linda Kerr, and Rebecca Fitzsimmons for their contributions to phenotypic characterization. They also thank Christelle Adolphe, Mehmet Akyuz, and Christian Michaels for critical reading of the manuscript.

Published by Bioscientifica Ltd. 


\section{References}

Adolphe C, Hetherington R, Ellis T \& Wainwright B 2006 Patched1 functions as a gatekeeper by promoting cell cycle progression. Cancer Research 66 2081-2088. (doi:10.1158/0008-5472.CAN-05-2146)

Allan GJ, Zannoni A, McKinnell I, Otto WR, Holzenberger M, Flint DJ \& Patel K 2003 Major components of the insulin-like growth factor axis are expressed early in chicken embryogenesis, with IGF binding protein (IGFBP) -5 expression subject to regulation by Sonic Hedgehog. Anatomica Embryologica 207 73-84. (doi:10.1007/s00429-003-0321-x)

Baker J, Liu JP, Robertson EJ \& Efstratiadis A 1993 Role of insulin-like growth factors in embryonic and postnatal growth. Cell 75 73-82. (doi:10.1016/S0092-8674(05)80085-6)

Bigelow RL, Jen EY, Delehedde M, Chari NS \& McDonnell TJ 2005 Sonic hedgehog induces epidermal growth factor dependent matrix infiltration in HaCaT keratinocytes. Journal of Investigative Dermatology 124 457-465. (doi:10.1111/j.0022-202X.2004.23590.x)

de Bont JM, van Doorn J, Reddingius RE, Graat GH, Passier MM, den Boer ML \& Pieters R 2008 Various components of the insulin-like growth factor system in tumor tissue, cerebrospinal fluid and peripheral blood of pediatric medulloblastoma and ependymoma patients. International Journal of Cancer 123 594-600. (doi:10.1002/ijc.23558)

Chen Y \& Struhl G 1998 In vivo evidence that Patched and Smoothened constitute distinct binding and transducing components of a Hedgehog receptor complex. Development 125 4943-4948.

Chen W, Tang T, Eastham-Anderson J, Dunlap D, Alicke B, Nannini M, Gould S, Yauch R, Modrusan Z, DuPree KJ et al. 2011 Canonical hedgehog signaling augments tumor angiogenesis by induction of VEGF-A in stromal perivascular cells. PNAS 108 9589-9594. (doi:10.1073/pnas.1017945108)

Diepgen TL \& Mahler V 2002 The epidemiology of skin cancer. British Journal of Dermatology 146 (Suppl 61) 1-6. (doi:10.1046/j.1365-2133.146.s61.2.x)

Ellis T, Smyth I, Riley E, Graham S, Elliot K, Narang M, Kay GF, Wicking C \& Wainwright B 2003 Patched 1 conditional null allele in mice. Genesis 36 158-161. (doi:10.1002/gene.10208)

Fan L, Pepicelli CV, Dibble CC, Catbagan W, Zarycki JL, Laciak R, Gipp J, Shaw A, Lamm ML, Munoz A et al. 2004 Hedgehog signaling promotes prostate xenograft tumor growth. Endocrinology 145 3961-3970. (doi:10.1210/en.2004-0079)

Fogarty MP, Emmenegger BA, Grasfeder LL, Oliver TG \& Wechsler-Reya RJ 2007 Fibroblast growth factor blocks Sonic hedgehog signaling in neuronal precursors and tumor cells. PNAS 104 2973-2978. (doi:10.1073/pnas.0605770104)

Gailani MR, Stahle-Backdahl M, Leffell DJ, Glynn M, Zaphiropoulos PG, Pressman C, Unden AB, Dean M, Brash DE, Bale AE et al. 1996 The role of the human homologue of Drosophila patched in sporadic basal cell carcinomas. Nature Genetics 14 78-81. (doi:10.1038/ng0996-78)

Gorlin RJ 2004 Nevoid basal cell carcinoma (Gorlin) syndrome. Genetics in Medicine 6 530-539. (doi:10.1097/01.GIM.0000144188.15902.C4)

Hahn H, Wicking C, Zaphiropoulous PG, Gailani MR, Shanley S, Chidambaram A, Vorechovsky I, Holmberg E, Unden AB, Gillies S et al. 1996 Mutations of the human homolog of Drosophila patched in the nevoid basal cell carcinoma syndrome. Cell 85 841-851. (doi:10.1016/ S0092-8674(00)81268-4)

Hahn H, Wojnowski L, Specht K, Kappler R, Calzada-Wack J, Potter D, Zimmer A, Muller U, Samson E \& Quintanilla-Martinez L 2000 Patched target Igf 2 is indispensable for the formation of medulloblastoma and rhabdomyosarcoma. Journal of Biological Chemistry 275 28341-28344. (doi:10.1074/jbc.C000352200)

Ingram WJ, Wicking CA, Grimmond SM, Forrest AR \& Wainwright BJ 2002 Novel genes regulated by Sonic Hedgehog in pluripotent mesenchymal cells. Oncogene 21 8196-8205. (doi:10.1038/sj.onc.1205975)
Jonkers J, Meuwissen R, van der Gulden H, Peterse H, van der Valk M \& Berns A 2001 Synergistic tumor suppressor activity of BRCA2 and p53 in a conditional mouse model for breast cancer. Nature Genetics 29 418-425. (doi:10.1038/ng747)

Lipinski RJ, Cook CH, Barnett DH, Gipp JJ, Peterson RE \& Bushman W 2005 Sonic hedgehog signaling regulates the expression of insulin-like growth factor binding protein-6 during fetal prostate development. Developmental Dynamics 233 829-836. (doi:10.1002/dvdy.20414)

Lobe CG, Koop KE, Kreppner W, Lomeli H, Gertsenstein M \& Nagy A 1999 $\mathrm{Z} / \mathrm{AP}$, a double reporter for cre-mediated recombination. Developmental Biology 208 281-292. (doi:10.1006/dbio.1999.9209)

Marsh D, Dickinson S, Neill GW, Marshall JF, Hart IR \& Thomas GJ 2008 alpha vbeta 6 Integrin promotes the invasion of morphoeic basal cell carcinoma through stromal modulation. Cancer Research 68 3295-3303. (doi:10.1158/0008-5472.CAN-08-0174)

Milenkovic L, Goodrich LV, Higgins KM \& Scott MP 1999 Mouse patched1 controls body size determination and limb patterning. Development 126 4431-4440.

Nakamura K, Sasajima J, Mizukami Y, Sugiyama Y, Yamazaki M, Fujii R, Kawamoto T, Koizumi K, Sato K, Fujiya M et al. 2010 Hedgehog promotes neovascularization in pancreatic cancers by regulating Ang-1 and IGF-1 expression in bone-marrow derived pro-angiogenic cells. PLOS ONE 5 e8824. (doi:10.1371/journal.pone.0008824)

Nieuwenhuis E, Barnfield PC, Makino S \& Hui CC 2007 Epidermal hyperplasia and expansion of the interfollicular stem cell compartment in mutant mice with a C-terminal truncation of Patched1. Developmental Biology 308 547-560. (doi:10.1016/j.ydbio.2007.06.016)

Palma V \& Ruiz i Altaba A 2004 Hedgehog-GLI signaling regulates the behavior of cells with stem cell properties in the developing neocortex. Development 131 337-345. (doi:10.1242/dev.00930)

Rao G, Pedone CA, Del Valle L, Reiss K, Holland EC \& Fults DW 2004 Sonic hedgehog and insulin-like growth factor signaling synergize to induce medulloblastoma formation from nestin-expressing neural progenitors in mice. Oncogene 23 6156-6162. (doi:10.1038/sj.onc.1207818)

Schlake T 2005 Segmental Igfbp5 expression is specifically associated with the bent structure of zigzag hairs. Mechanisms of Development 122 988-997. (doi:10.1016/j.mod.2005.04.012)

Shaw A, Gipp J \& Bushman W 2010 Exploration of Shh and BMP paracrine signaling in a prostate cancer xenograft. Differentiation 79 41-47. (doi:10.1016/j.diff.2009.08.009)

Siggins SL, Nguyen NY, McCormack MP, Vasudevan S, Villani R, Jane SM, Wainwright BJ \& Curtis DJ 2009 The Hedgehog receptor Patched1 regulates myeloid and lymphoid progenitors by distinct cell-extrinsic mechanisms. Blood 114 995-1004. (doi:10.1182/blood-2009-03-208330)

Villani RM, Adolphe C, Palmer J, Waters MJ \& Wainwright BJ 2010 Patched1 inhibits epidermal progenitor cell expansion and basal cell carcinoma formation by limiting Igfbp2 activity. Cancer Prevention Research 3 1222-1234. (doi:10.1158/1940-6207. CAPR-10-0082)

Wicking C \& Bale AE 1997 Molecular basis of the nevoid basal cell carcinoma syndrome. Current Opinion in Pediatrics 9 630-635. (doi:10.1097/00008480-199712000-00013)

Yakar S, Liu JL, Stannard B, Butler A, Accili D, Sauer B \& LeRoith D 1999 Normal growth and development in the absence of hepatic insulin-like growth factor I. PNAS 96 7324-7329. (doi:10.1073/pnas.96.13.7324)

Yauch RL, Gould SE, Scales SJ, Tang T, Tian H, Ahn CP, Marshall D, Fu L, Januario T, Kallop D et al. 2008 A paracrine requirement for hedgehog signalling in cancer. Nature $\mathbf{4 5 5}$ 406-410. (doi:10.1038/ nature07275)

Received in final form 12 November 2012

Accepted 29 January 2013

Made available online as an Accepted Preprint

12 February 2013

Published by Bioscientifica Ltd. http://erc.endocrinology-journals.org

DOI: 10.1530/ERC-12-0307
(C) 2013 Society for Endocrinology Printed in Great Britain 